\title{
CHAMPIONING THE COMPLIANCE MODEL: FROM COMMON SENSE TO COMMON ACTION?
}

\author{
Kersty Hobson
}

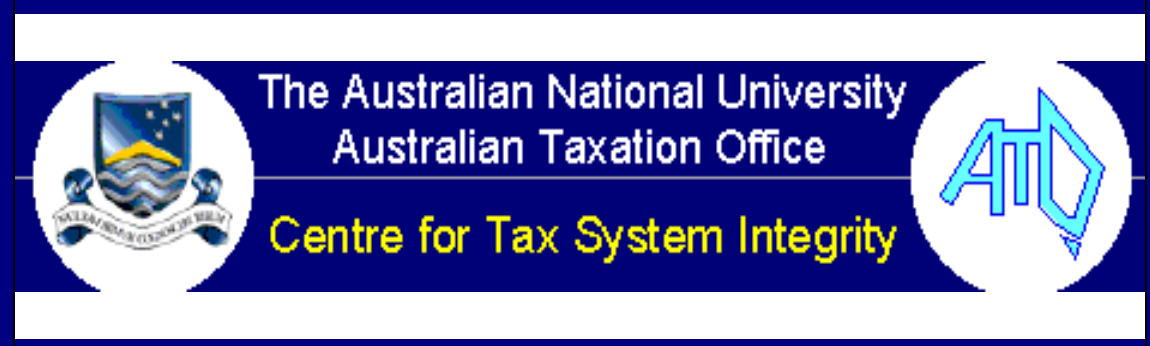

WORKING PAPER No 28

December 2001 


\title{
CHAMPIONING THE COMPLIANCE MODEL: FROM COMMON SENSE TO COMMON ACTION?
}

\author{
Kersty Hobson
}

SERIES EDITOR

Tina Murphy

\author{
Centre for Tax System Integrity \\ Research School of Social Sciences \\ Australian National University \\ Canberra, ACT, 0200
}

ISBN 0642768277

ISSN 1444-8211 
(C) Centre for Tax System Integrity, Research School of Social Sciences, Australian National University 2001

(C) Commonwealth of Australia 2001

National Library of Australia

Cataloguing-in-Publication data:

Hobson, K., 1971 -

Championing the compliance model: From common sense to common action?

Bibliography

ISBN 0642768277

1. Australian Taxation Office - Management. 2. Tax administration and procedure - Australia. 3. Taxpayer compliance - Australia. I. Murphy, Tina. II. Centre for Tax System Integrity. III. Title. (Series: Working paper (Centre for Tax System Integrity); no. 28).

352.440994

If you would like to make any comments on this working paper please contact the author directly within 90 days of publication.

\section{Disclaimer}

This article has been written as part of a series of publications issued from the Centre for Tax System Integrity. The views contained in this article are representative of the author only. The publishing of this article does not constitute an endorsement of or any other expression of opinion by the Australian National University or the Commissioner of Taxation of the author's opinion. The Australian National University and the Commissioner of Taxation do not accept any loss, damage or injury howsoever arising that may result from this article. This article does not constitute a public or private ruling within the meaning of the Taxation Administration Act 1953, nor is it an advance opinion of the Commissioner of Taxation. 


\section{THE CENTRE FOR TAX SYSTEM INTEGRITY WORKING PAPERS}

The Centre for Tax System Integrity (CTSI) is a specialized research unit set up as a partnership between the Australian National University (ANU) and the Australian Taxation Office (Tax Office) to extend our understanding of how and why cooperation and contestation occur within the tax system.

This series of working papers is designed to bring the research of the Centre for Tax System Integrity to as wide an audience as possible and to promote discussion among researchers, academics and practitioners both nationally and internationally on taxation compliance.

The working papers are selected with three criteria in mind: (1) to share knowledge, experience and preliminary findings from research projects; (2) to provide an outlet for policy focused research and discussion papers; and (3) to give ready access to previews of papers destined for publication in academic journals, edited collections, or research monographs.

Series Editor:

Tina Murphy 


\begin{abstract}
The Compliance Model was introduced into the Australian Tax Office (Tax Office) as both a procedural and product-outcome innovation, where it has been met with varying degrees of acceptance and criticism. This paper analyses interviews with 22 Compliance Model 'champions', to examine what the Compliance Model meant to them and how they put it into practice. It shows how champions believed the Compliance Model was 'common sense'. It represented and brought together various trains of thought and ideas they already had about how they wanted to work. Champions were able to put these thoughts into action, as the Model legitimised their beliefs and gave them a new language - or 'discursive space' - in which they could try and do things differently. Working from 'within' the Model, it became a new way of thinking. They were able to see the positive effects of using the Compliance Model and became committed to using it as a tool for encouraging sound working practices and greater taxation compliance. This suggests that the Compliance Model could be taken forward in the Tax Office by putting into action small, day-to-day, behavioural changes that exemplify the conceptual foundations of the Model, without having to change staff 'values' or 'culture'. By bringing the Compliance Model gradually to life, Tax Office staff could experience first-hand the positive effects of the Model, which, for the champions at least, was the strongest factor in committing them to its validity as a worthwhile form of practice.
\end{abstract}




\title{
Championing the compliance model: From common sense to common action?
}

\author{
Kersty Hobson
}

\section{INTRODUCTION}

\begin{abstract}
A 'champion' has status or clout and advocates on behalf of others. Champions, in fact, help legitimize the idea originator, serving as a bridge or translator between sometimes unconventional originator (ideator or inventor) and the more traditional organization. (Rosenfeld \& Servo 1990: 54).

'When you' re pioneers, it's always difficult and you feel as if you're up against it or you're walking on quicksand. But when it all happens, it all just clicks into place, and my belief is it will click into place. It's just a matter of finding that switch that will make it happen.' (quote from Tax Office champion interview).
\end{abstract}

This paper examines change 'champions' in the Australian Tax Office (Tax Office). Specifically, it explores why certain Tax Office staff members have become the champions or advocates of the Compliance Model, a tax compliance innovation introduced into the Tax Office through collaboration with researchers at the Australian National University. It seeks to understand why Tax Office champions chose to become the 'translators' of the Compliance Model, as the above Rosenfeld quote suggests, and why, despite many barriers, they had faith that change would prevail, as the second quote suggests. Specifically, this paper seeks to examine how these individuals understood and made use of the Compliance Model; and what this can tell us about how the Tax Office might take the Compliance Model forward.

Why focus on the Compliance Model champions? First, the presence of motivated individuals who advocate and advance new ideas is believed central to operationalising positive change within an organisation (see Bouwen \& Fry 1988, Rogers 1995, Shover et al. 2001). Much has been written about the personalities and practices of these innovators. Yet most research has taken place in the corporate sector where innovation and profit margins are key operational and behavioural drivers (Damapour \& Gopalakrishnan 2001). The public service has remained a relatively uncharted area of inquiry, yet employs a significant proportion of the workforce (see Australian Bureau of Statistics 2001), who are charged with delivering timely, effective and efficient public policy through large-scale organisational 
structures ${ }^{1}$. Therefore, studying champions in the Tax Office offers a rare glimpse of how individuals innovate in a public service department. Second, research often focuses on the adoption of new ideas that have been generated within an organisation (West \& Farr 1990). By contrast, the Compliance Model was formed through independent academic research, that was developed within the Tax Office context (see Shover et al. 2001) for details of the history and development of the Compliance Model). Studying the Compliance Model offers an opportunity to examine how such an externally generated model is adopted and translated into meaningful practice by individuals within an organisation - a process that may become important to understand further as partnerships between universities and public organisations grow in the face of changing knowledge climates.

Finally, there is the type of innovation that the Compliance Model represents.

Innovation is usually defined as the adoption of an idea or behaviour, pertaining to a product, service, device, system, policy, or programme, that is new to the adopting organization. (Damapour \& Gopalakrishnan 2001: 47).

Thus innovations normally pertain to either changes in products or changes in processes (Damapour \& Gopalakrishnan 2001). A product is goods or services offered to a client, whilst a process is the mode of production or delivery of goods or services. The majority of literatures about innovation and change in organisations focus around the introduction of new technologies or systems of production in industry (see Rogers 1995). By contrast, the Compliance Model is both a product and a process - a 'soft' (ways of thinking, Tax Office philosophy) and 'hard' (routine practices, services, publications) form of change (Harrisson et al. 2001). The rationale of the model is to encourage Tax Office staff to treat taxpayers as individuals who are embedded in specific contexts. This perspective affects processes, whilst also making Tax Office staff think pre-emptively about how to write and target their literatures, affecting products. As a result, it is an 'outward-looking' innovation that cuts across organisational boundaries, and has ethical and value implications for its practitioners and for taxpayers. This makes it an unusual form of organisational innovation and one worthy of further investigation.

\footnotetext{
${ }^{1}$ For example, the Tax Office seeks to maximise revenue through efficient operational structures, similar to private industry. It differs in its role of administering tax law and being directly implicated with issues of procedural and distributive justice.
} 


\section{STUDYING COMPLIANCE MODEL CHAMPIONS: EPISTEMOLOGICAL APPROACHES TO CHANGE}

Change is now a part of professional organisational life (Bouwen \& Fry 1988, Kanter 1983, Kanter 1989). The seemingly constant redrawing of management structures, work practices and company policy can be understood partially through the impacts of global market forces and decrease in international trade barriers (see Klein 2000, Harvey 2000). Added to this, change has become part of modern workplace 'culture', where innovation and the active seeking of new ways of operating thrives in an effort to increase efficiency, profits and 'add value'. Management practices in countries such as the USA, UK and Australia have in the past few decades changed from those of 'command and control', to embracing forms of 'transformational leadership' (Hooper \& Potter 1999). As Hinchliffe (2000: 579) summarises:

Hierarchy has been displaced by a taste for heterarchy. Enabling conditions are talked about instead of fixed structures. Corporate employees have been dropped in preference for enterprising individuals. Movement and initiative have, in some quarters, become more valued than stasis and knowing one's place.

These changes apply mostly to the private business sector, where there is more flexibility to innovate and experiment in comparison to civil service sectors, which must deliver tightly defined services to the government and its citizens. In short, increasing profit margins and capturing market segments implies experimentation whereas tax administration does not. However, the development and adoption of the Compliance Model is a form of innovation in terms of tax system administration that has potentially far-reaching implications for the Tax Office and the way that tax, as a form of social practice, is viewed in Australia.

How then is change or the effects of the introduction of the Compliance Model to be studied? The scope of conceptual frameworks to choose from is vast. Possible perspectives include looking at the ways in which the types of organisational structures and procedures in the Tax Office promote or stifle innovation (Bouwen \& Fry 1988, Harrisson et al. 2001, Kanter 1983); or examining the salient characteristics of the Compliance Model, to assess its 'adoptability' (Damapour \& Gopalakrishnan 2001, Rogers 1995). Also possible is studying how factors external to the Tax Office promote innovation within the organisation (Hollingsworth 2000); the key practices or characteristics of champions (Hooper \& Potter 1999, Rogers 1995); or different stages in the process of creating and adopting the 
Compliance Model (King 1990, Rogers 1995). Thus, the innovation, the organisation, the context, or the personalities involved are all potential subjects of study, either in isolation or as cause-and-effect variables.

Yet taking a contrasting epistemological approach could potentially be highly beneficial when asking questions about individual's understanding and translation of an abstract concept such as the Compliance Model. Welford (1998) has argued that organisational researchers are too quick to adopt the prevailing epistemologies of contemporary management theory, thus limiting the questions that can be asked about organisational change. Change processes and outcomes can be studied using the tools of mathematical modelling (Visser 2000), psychology, and systems (King 1990), to name but a few. Yet, it is important to understand that underpinning the above body of research are implicit assumptions about the functioning and structuring of organisations and individuals. For example, organisations are normatively mapped out as structural entities, which are:

Rational collectivities of social actors engaged in purposive goal-oriented activities within the domain of a clearly defined boundary. (Boden 1994:15)

This positivist approach could tell the following story of Compliance Model champions. The Compliance Model appeals to certain Tax Office staff's values and attitudes. These values are either changed or evoked, and are then translated into altered behaviour, as long as personal or institutional barriers do not stand in the way (for example, see Fishbein 1993, Terry et al. 1993). Although this is a gross simplification of the positivist story, it is worthwhile asking if there is another story to tell and whether the Compliance Model, being the type of innovation it is, benefits from the adoption of a different epistemological approach. This paper takes the position that indeed there is another approach worth taking as the Compliance Model is not a discrete or bounded innovation whose effects can be tracked through indicators such as increased output or product quality alone (although these factors could offer some information on the impact of the Compliance Model on the Tax Office). Instead it is an idea about ways of acting and thinking, whose translation requires turning it into meaningful practices, set within the everyday contexts of the Tax Office. In this sense, it is 'below the line' of most organisational change studies. This means it requires treating champion's ideas, thoughts and experiences of the Compliance Model as instrumental to its 
enactment, not merely as incidental or anecdotal to the 'real' changes taking place. It therefore warrants an approach that places individual social practices as a central part of a conceptual framework.

\section{Organisational change and the critical social sciences: The road less travelled?}

Despite a slow uptake of this approach in the academy, critical social sciences can be highly informative in unravelling organisational practices and change (for example see Harrisson et al. 2001, Stubbs 2000). Rather than casting organisations as static, structural entities within which workers slot into immutable roles, organisations are instead viewed as on-going processes, constantly re-created through norms, values and expectations (Hollingsworth 2000, Kanter 1983). This position comes under the broad framing of social constructionist or anti-reductionist approaches (Sibeon 1999), which posit that investigating how people think and behave requires addressing values, beliefs and cultural assumptions, and how these all relate to cultural meanings (Reser 1995). These relate not only to the organisational context of investigation but also to the broader social contexts of the individual actor (see Finger 1994, Giddens 1991: see also Edwards et al. 1995, Burningham \& Cooper 1999 for further discussion of social constructionist approaches).

One theory that is very useful in understanding this approach is Anthony Giddens' structuration theory (1984). Structuration theory focuses on the on-going processes of social life and their role in constituting patterns of ordering at all levels of society. Giddens basically argues that recursive and routine actions (a form of knowledge called practical consciousness) and awareness or knowledge that is verbally or cognitively expressed (called discursive consciousness) form the bedrock of social life. What we all know about how to 'go on' in everyday life and what we can give discursive vent to are not incidental to how society is structured and functions. Rather, they are the very processes that shape our 'here and now', and future practices. This approach places human knowledge at the centre of social processes, in that the recursive nature of practices creates conditions of future actions, through both their intended and unintended consequences.

This process is represented in Figure 1. It shows that through on-going practices, the consequences of actions feed back into social reproduction across periods of time, creating sets of social conditions that are beyond the intentions and remit of particular actions. 


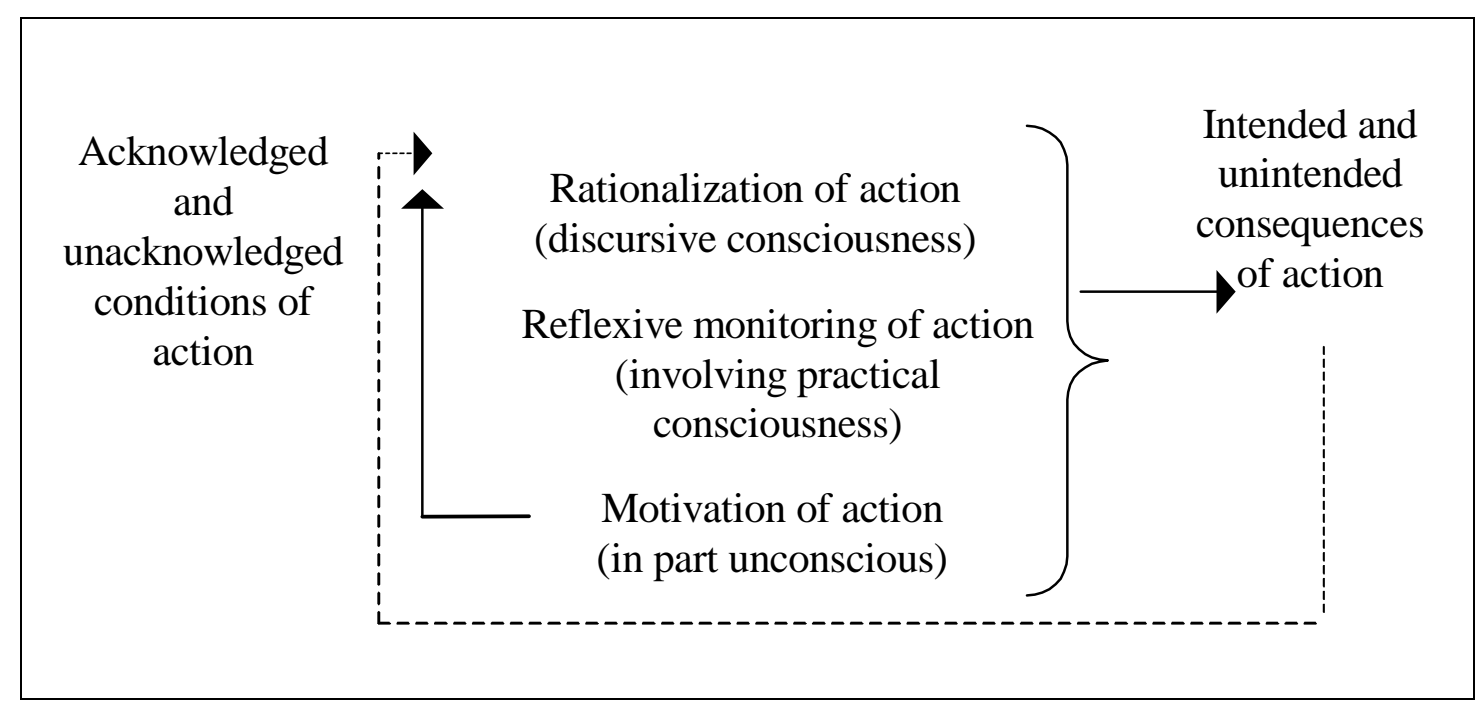

Figure 1. Concepts from Giddens' structuration theory (Bryant \& Jary 1991)

To give an example, a tax officer may carry out sets of routine practice on a day-to-day basis that are based on a great deal of 'hidden' knowledge (practical consciousness). This may include sending out letters to taxpayers or entering data onto a computer system. Taken-forgranted knowledge is expressed in these actions, some of which may be verbally shared and recreated with other Tax Office staff (discursive consciousness) through informal conversations and team meetings. These practices have set intentions (such as to collect revenue and promote compliance) but they also have other outcomes that are not directly intended, perhaps affecting taxpayer's views of the Tax Office and institutionalising certain practices through their constant use. The combination of intended and unintended outcomes sets the scene for, and both constrains and enables, the future conditions of action.

Using this framework to ask questions about the Compliance Model champions is pertinent as it is this process, of understanding the ramifications of Tax Office practices on the taxpayer and on the legitimacy of the tax administration as a whole, that the Compliance Model ultimately aims to address. Thus, how Giddens constructs social ordering and the issues that the Compliance Model aims to address are closely related. They both place as central the need to understand what individuals know and how they act, and the effects of these actions on others. This framework, or epistemological outlook, will be used here to examine the champion's understandings and rationality, to unravel the forms of knowledge they bring to their work with the Compliance Model, and also to examine the implications of the champion's actions for the Tax Office. 


\section{RESEARCH METHODS}

The above epistemological stance presupposes the use of certain research methods and forms of analysis, which are qualitative. This research was conducted using one-to-one interview methods as part of an on-going investigation by researchers at the Centre for Tax System Integrity (CTSI) into the impact of the Compliance Model on the Tax Office (see Shover et al. 2001 for other aspects of the research). Interviewees were selected using a 'snow-balling' method. That is, key individuals known to the Tax Office team implementing the Compliance Model were interviewed and in the process were asked to recommend others who might be interested to talk about the model, whether their outlook was positive or negative. This resulted in 22 tax officers being interviewed (17 male, 5 female $)^{2}$. The managerial scope of interviewees ranged from the most senior levels to APS 6 (one level below junior middle management), although the majority were clustered around the rank of senior management and top middle management.

All interviews were semi-structured, to allow data comparable to other CTSI Compliance Model research to be drawn, whilst also allowing interviewees the space to talk openly. Questions asked included interviewee's understanding of the Compliance Model, any positive and negative experiences they had of trying to implement the model in the Tax Office, other Tax Office staff's understanding and support of the model, and also how implementation of the model might be improved in the future. All interviews were taped and transcribed. In the analysis the interviews were coded to provide data on the percentages of answers to each question (see Hobson forthcoming). This paper however is based on a less predetermined process of open coding, which aimed to enable the key themes to emerge from the data (see Strauss 1987 for further discussion of this process).

\footnotetext{
${ }^{2}$ Interviews were carried out by members of the Centre for Tax System Integrity and the Regulatory Institutions Network, Australian National University. Interviewers were Brenda Morrison, Tina Murphy and Declan Roche.
} 


\section{RESEARCH FINDINGS: 'UNDERSTANDING' THE COMPLIANCE MODEL}

Moscovici (2001) argues that when examining others understanding of an idea, such as the Compliance Model, the question should not be whether they are 'right' or 'wrong' but rather how their understanding has come about. That is, research is not about testing to see if subjects have the 'correct' information. Rather, it should concern how this information has been formulated into knowledge or meaningful representations (Ehrlich et al. 1999). This is a transformation from the abstract into the actionable, and implies a process of moving information to knowledge, which is not simply about information retention but involves meaningful translation (Hinchliffe 2000).

To explain this point further, many champions could not recall thoroughly the contents of the

Compliance Model, although all stated they felt they had a good 'understanding' of it. How it had been explained and represented to them in meetings and presentations was often referred to vaguely as 'that triangle'. Some seemed surprised they could not recall a concept that had become important to their work or felt concerned that they may have got it wrong, saying:

'I hope my understanding of the Compliance Model is the right one.'

The contradictions this threw up in the interviews were interesting. In one, the individual gave a thorough and multi-faceted explanation of their understanding of the Compliance Model:

'So I see the model gives quite clear levels and responses and it lets you take into account individual's personal circumstances, so people at the end of the day feel they are being properly treated. They have been listened to, they have had an opportunity to debate the issue. At the end of the day they might feel that they don't like the answer but they think they had a proper hearing... But on the other side too, I think it's about understanding industries and individuals and the drivers within an industry to help us know how to target our approaches and educational material, or enforcement activity or the balance of those sorts of activities. So it's really about...an individual interacting with the system - treat them in a professional, personal way, but also enable the ATO to understand the various business sectors.' 
Yet, later the same interviewee said, when asked what the Centre for Tax System Integrity can do to help the Tax Office:

'Well, I would think just helping understand it more deeply...maybe a refresher course or a refresher discussion that would actually help. Because everyone gets very busy focused on outcomes and things.'

This contradiction could be interpreted as the champions being those who have paid the model the loudest lip service. Or, maybe the Compliance Model had become such a part of their thinking, straddling the boundary of practical and discursive consciousness, that the central tenets of the Compliance Model were now part of their taken-for-granted knowledge. This latter reasoning is a feasible conclusion to draw, and is discernible by taking a closer look at what the Compliance Model represented to champions.

\section{The Compliance Model: Common sense distilled}

Many interviewees stated that their initial reaction to the Compliance Model was that it made intuitive common sense:

'It all fell into place.'

'And so it was just very intuitive to me.'

'I just thought it was common sense. I liked the fact that it brought a lot of things together I suppose. That here is a model, and you need to be able to place your client on that pyramid, but before you did that you needed to understand what he's on about in that context of the BISEP ${ }^{3}$. I thought it was sort of tidy, sort of academic but at the same time it looked very practical to me.'

This emphasis on 'common sense' and intuitive reasoning is noteworthy. It suggests that for these individuals, the Compliance Model had an internal logic that is immediately selfevident. It created an almost immediate sense of recognition. This recognition occurred because the messages of the Compliance Model were in strong accordance with the individual's ideas and hopes about how the Tax Office should or could be operating. Some said that it was a crystallisation of their own, often disparate, aims and plans, and that by

\footnotetext{
${ }^{3}$ BISEP represented the idea that to understand the compliance of an individual or group, one needed to understand the lifespace in which they operated. The initials of this acronym stand for $\mathrm{B}=\mathrm{Business}$ profile, I= Industry factors, $\mathrm{S}=$ Sociological factors, $\mathrm{E}=$ Economic factors and $\mathrm{P}=$ Psychological factors.
} 
harnessing all the model had to offer, they could build upon previous work, or at least head in favourable directions:

'And the thing that struck me was that, it was funny but I don't know what was new about it. That was always my attitude, all the way back but I just said "right, they have finally formalised it and that's the way to go now" which is great. Our whole team were pretty keen on it.'

'Without blowing any trumpets, that was how I thought it should have been and I was actually amazed why the tax office was always reluctant to actually show people what to do. I remember at school they used to teach us that in law and I thought if you get a chance, why not do it? They are now doing it which is sensational.'

This can be seen as an indication that the Compliance Model is a fundamentally sound model, as it reflected back to staff their experiences and views of the world, which are instantly graspable. What seemed to appeal to these champions was not just the central messages of the Compliance Model, as many believed they were already trying to work with them, but how it brought together, merged and represented these ideas. That is:

'It's all very sensible. It made a lot of sense. In my view it's probably what we have been applying in a practical sense but had never documented in a coherent and a comprehensive way.'

Thus, on one level the Compliance Model appealed, as it brought together the ideas and ideals that seem to have been part of these champions practical consciousness for a long time. It not only brought them to the awareness of individuals, but also enabled connections to be made between often-scattered ideas and bits of knowledge. This is an important process as:

Pointing out connections between previously isolated bits of people's assumptions can create both greater awareness of those bits and new cognitive links among them (Strauss \& Quinn 1997: 40).

For some, there was almost a 'Eureka!' moment, where a sense of clarity was gained about their own knowledge. However, the Compliance Model is more than just an idea that appealed to champions because it legitimised their worldview. It also provided them with a new discursive tool they used to talk about and, thereby hoped would help bring about changes in the Tax Office. 


\title{
The discourse of the Compliance Model
}

Over a quarter of interviewees directly stated they saw the Compliance Model as a form of philosophy, a framework or a touchstone, which they could use to inform their outlook and guide their practices:

\begin{abstract}
'At the end of the day the Compliance Model is really a qualified philosophy, principles as to how you want to behave and it gives you the tool in which to react to different levels of position of choice. And by having that sort of a positive attitude and understanding you will then be able to maximise on relationships, be it private, professional or otherwise.'
\end{abstract}

The introduction of the Compliance Model into the Tax Office was timely as it fitted neatly into ongoing discourses about reshaping the tax system and how it is administered. This discourse -which is commonly defined as a form of argument or 'group of utterances which seem to have a coherence and a force to them in common' (Mills 1998: 7) - is directly related to the introduction of the Taxpayers' Charter. The Compliance Model also resonated with the recently released Public Service Code of Conduct (see Public Service and Merit Protection Commission 2000) and other tax reforms that had taken place within the Tax Office over the previous few years (see Shover et al. 2001). In line with these initiatives, the Compliance Model embodied ideals that Tax Office should do more than collect revenue by concerning itself with building community confidence and partnerships. Thus, the Compliance Model was very much:

'...in full alignment with the Taxpayers' Charter. We are clear that we are dealing with the individual taxpayer, and the circumstances of taxpayers need to be examined and not just put all in one big group and say "everything is the same, everything applies to that group".'

'The last two years the Compliance Model has been specifically mentioned in our corporate plan in different contexts, and it's particularly compatible with the Taxpayers' Charter goals. In the early days when we were communicating the Compliance Model to staff we had a lot of success linking it with the Taxpayers' Charter and using it to support its goals.'

Thus, the Compliance Model fitted the general direction in which Tax Office managers and business planners wished to head. However, the discourse of the Compliance Model was not only in-keeping with conceptual currents in the Tax Office. It also provided new ways for the champions to think about and create 'space' within the Tax Office, in which they could do things differently. 
The Compliance Model was a new way of talking and communicating with others. For example, one interviewee called the Compliance Model a 'tool to talk'. Another interviewee stated how it had given space, or 'permission' to those who wanted to air views about how to do their job differently. Another saw it as giving staff a 'bit of paper' to overtly show how they were taking the community into account, in adopting an ethical stance in interactions with taxpayers. Thus, it was not only what the model represented that was important, but also the institutional space it afforded champions to rethink their practices and future direction. Where once staff's cries of 'we should do things differently' may have fallen on deaf ears, champions now had a hook to hang their beliefs on - 'the Compliance Model says...'- which legitimised their positions and gave them the green light to try different approaches:

'We were certainly open to trying new things and looking for new ways of operating because we had been doing the same thing for so long. It was really along some of the lines we've been heading or trying to head anyway, but it probably just put some structure around that.'

For those who had worked hard at trying to 'sell' the principles of the Taxpayers' Charter within the Tax Office, the Compliance Model was a new bow to their arrow:

'And what the model did was gave me a way of telling stories.'

It also presented the opportunity, if not the outcome, for the Tax Office to reach a common 'lexicon of language', in terms of understanding and sharing common principles and practices. In this way, the Compliance Model can be framed as a 'social representation', which is a form of shared knowledge that is produced and communicated through social processes, moving from the abstract to common sense or common dialect, through interaction (see Moscovici 2001, Billig 1993, Farr 1993, Jaspars \& Fraser 1984, Kruse \& Schwarz 1992). Although there is not the space to develop this argument further here, Lalli's (1999) assertion that social representations reconstruct common sense in local (everyday) situations and can therefore be seen as the 'local operators of common sense' is an interesting one that merits future consideration in relation to organisational innovation.

The Compliance Model also positioned champions and the Tax Office in broader business discourses. Senior staff were only too aware of the trends occurring in international management practices, and felt that the Compliance Model allowed them to take their place in this arena. Again, this is a sense of legitimation, of being an international 'player', shown 
by the many references made to how other countries were working with these issues and how using the Compliance Model put the Tax Office 'ahead' in terms of being pro-active and forward-thinking:

'I can recall we had some visitors from the UK last year and I remember at the end of the week and a half he said it was one of the best and most exciting things he'd seen, the Compliance Model. So he was taking it back to the UK.'

The fact that the Compliance Model is based on research from outside the Tax Office made it exciting to some champions, and enabled them to feel they are part of 'something' beyond the boundaries of the Tax Office:

'When I spoke to some staff and to others, you were able to say 'This is not just the Tax Office saying this, this has come from worldwide research of regulatory practices!'

This process appeared to allow staff to feel more comfortable with themselves and their social role. Instead of being the dreaded tax collector, commonly perceived as making unreasonable demands on honest people, they instead felt that the Compliance Model allowed them to help taxpayers and some have experienced members of the community warm to them as they do. In sum, they felt more liked and happier in their jobs:

'I must say that it is far more pleasant work to do than actually go through someone like a dose of salts.'

Examples were given in the interviews of how changing simple procedures had made their jobs more tolerable, such as altering the tone of lodgment letters, as referred to in the following quote:

'Not only did we get better lodgment outcomes but, more significant when I think what we got, was that when people rang up they were nice. They didn't ring up and abuse you for sending them a nasty letter, they rang up and they were nice.'

This enabled Tax Office staff to adopt discourses that may previously have seemed incongruous coming from a tax officer. For example, interviewees talked about bringing to their workplaces practices based on the concepts of human dignity, openness and respect, in keeping with the tenets of the Compliance Model. 
Adopting the Compliance Model also helped to reshape the public face of the Tax Office, according to the champions. One interviewee talked of how working with the Compliance Model required staff with different personality traits and outlooks than the old command and control style of auditing. As a result:

'I know there's a certain number of jobs that we have advertised in the last 12 months or so in the preparation for the GST workload that have explicitly included within the selection requirements those sorts of traits'.

Several other interviewees commented on how recruitment candidates were now tested for their understanding of the Compliance Model in the selection process. This appeared to give the champions the feeling that they were no longer just recruiting auditors and administrators but that there was something special and different about the new staff coming into the Tax Office. As a result, it was at least hoped that these new people and new outlooks would gradually change the face and the feel of the organisation.

\section{Thinking about and with the Compliance Model}

The above argument is not intended to portray the Compliance Model as a way of talking that was adopted by champions in a distanced, self-interested sense, to simply get what they want. Rather, the adoption of the discourse of the Compliance Model, for all its attendant benefits, was part of the process of internalisation. That is, there was a subtle but important distinction in the Compliance Model interviews between those who thought about the Compliance Model and those who thought with it.

As already discussed above, it appeared that those who had a deep understanding of the Compliance Model could not always remember much about its abstract form. This did not denote a lack of comprehension, as interviewees displayed an understanding of the Compliance Model that went beyond merely repeating its contents, to grasping its complexity, ambiguity and potential ramifications. This was because they viewed the model dynamically. Indeed, it was applied dynamically and was adapted into various useable guises. 
For example, one interviewee talked about having used the Compliance Model as an educational tool to talk to taxpayers:

'When I was doing real time reviews, as part of an explanation to the taxpayer, I used to explain the Compliance Model. I'd just draw a little triangle, fairly basic and I explained it from a soft angle to them. And a lot more people after that explanation would accept the fact that even if they were audited there's a reason behind it.'

Most champions did not always use the model in such an overt way, as they had internalised it as 'another way of thinking'. For example, one interviewee described how they used the ideas of the model on Tax Office staff, such as to inform approaches to internal training. Indeed, some champions believed that it was only when they had stopped making overt reference to the model, when it had been digested and had become second nature, that they had truly understood it:

'It's not a model that you can pick off the shelf sometimes and use, it's more just a part of the way we do things. So I think we would consider it to be a success if we had all the elements of the model embedded in our work practices without calling it a model any more.'

This is because:

'It's not a set of rules, it's a philosophy.'

Thus, these champions were suggesting that the Compliance Model had become embedded in their practices, making it 'a cultural thing', as one interviewee referred to it. Or:

'It's not so much the model or anything but it's just been accepted as a way we actually go about doing things now.'

This differed from those who thought about the Compliance Model. From this second perspective, the Compliance Model triangle was used to locate individual positions in the Tax Office, to understand where their work practices fit in and where taxpayers sit. This, however, caused no end of confusion, as it suggested a static interpretation of the model. As the following quote suggests, when the model was presented to some staff:

'The understanding of the model was not always good and we did get a lot of people who thought what it meant was you didn't respond appropriately to non-compliance. People tended to think statements like 'we treat people as honest unless we know otherwise' meant that even though the overwhelming evidence was that they' $\mathrm{d}$ been diddling and telling fibs, we would have to accept them as honest. That, I think, is an area where the subtleties of the model are not always well understood.' 
This distinction was made well by one interviewee. He compared staff who had to use the model to plan business (and therefore had come to understand the Model through 'playing' with it) with ground staff who had 'mapped' themselves onto the model and used it to locate where they are in reference to others in the Tax Office:

'So at the rank and file level people map themselves on a model which I suppose is a human tendency to find where I fit. They don't see it as sort of dynamic - that if you fit here, that's where I live and that's where I am staying and that there isn't a role upwards or downwards in it.'

As the Compliance Model is a triangle shape, some Tax Office staff appeared to think it suggested all Tax Office compliance work should to be located at the bottom, 'soft' end of the Model, forsaking prosecution for education. In this way, they saw the Compliance Model as providing the Tax Office with a:

'...visual sense of proportion as to what the ATO wants and where we'd like to go.'

In one sense this is true. The Compliance Model does encourage Tax Office staff to use the tools of education and persuasion with taxpayers. However, this reading also meant that many Tax Office staff did not see the model as applicable to them. Others saw it as a threat to the work they did:

'A lot of people see it as the Compliance Model moving from an audit environment to a help and education environment and a lovey-dovey rose coloured glasses situation. But again, if you step back, it's not that at all, if you really understand what it's all about.'

This 'thinking about' reading of the model created a whole host of problems. Because interviewees had tried to apply the principles of the Compliance Model in a rigid way, not adapting it but sticking to its original abstract format, they had great difficulty matching it up with their everyday realities within the Tax Office. In this sense, these individuals (a few of the champions but mostly reportage from champions about others) talked about using the Compliance Model as if they are laying siege to the Tax Office. The interviewees with this outlook talked as if they were pushing an idea against great resistance, continually 'belting it over the head' to try and get the message across. This kind of 'pioneer spirit', adventurous as it may appear on the surface, was a rather impoverished translation of the Compliance Model in comparison to those who had made it actionable through the internalisation processes. The 
distinction between these two ways of seeing the Compliance Model is sketched out in Figure 2 below, which presents this argument mapped onto a simplified version of the Compliance Model (see Shover et al. 2001,for a more complete diagram of the Compliance Model).

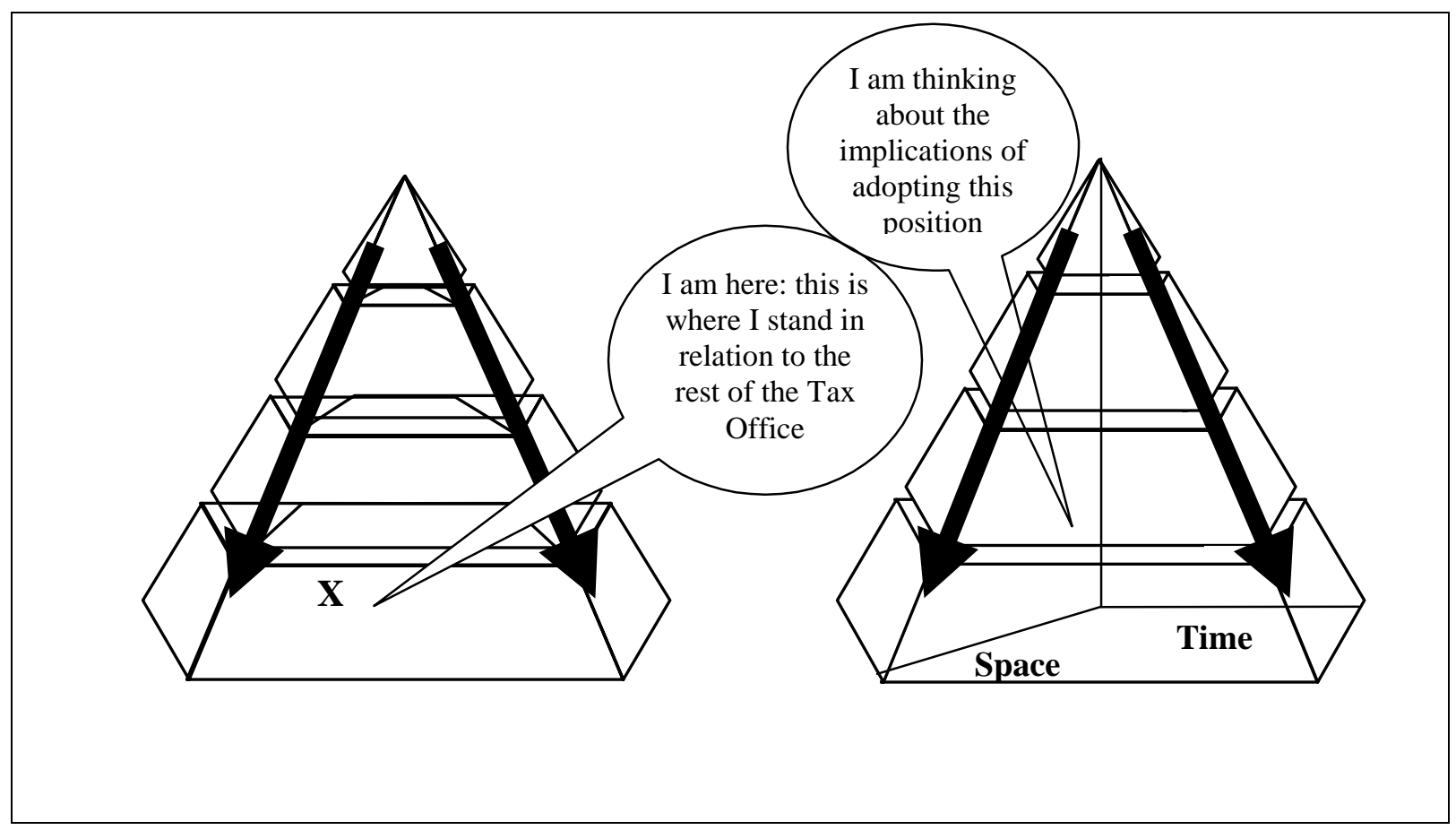

Figure 2: 'Thinking about' and 'thinking with' the Compliance Model

The first figure on the left shows an interpretation of the Compliance Model that is onedimensional, the 'I am here' or the 'taxpayer is here' reading of the model and its behavioural implications. The second figure on the right shows how champions who have internalised the Compliance Model as a way of thinking saw it as multi-dimensional. This was not about using the model to position oneself in the Tax Office (that is, I am at the soft/hard end) but rather thinking 'inside' the model about how their practices affect outcomes, in reference to both temporal and contextual factors.

To explain the right-hand side of Figure 2 further, the implications of the Compliance Model were seen as spanning a wide array of contexts, which affect each other incrementally. This applied both to Tax Office staff practices, in terms of actions and material, as well as to a wide array of social relations, both personal and professional. One interviewee talked about how ideas embodied in the Compliance Model were used by some staff to think about how 
they might alter senior manager behaviours in relation to their acceptance of the model. This resulted in the formulation of a strategy for dealing with managers' outlooks, which was based on the principles of the model. As another interviewee aptly stated:

\footnotetext{
'We work inside the model. Now, if we interpret the model as one dimension, we could have a self-fulfilling prophecy. We prosecute them, they get angry, they don't lodge. It's a catch-22, it's a circular argument. So by looking at the compliance model a little bit more strategically, you can add that extra dimension where at the moment it doesn't work.'
}

This was about seeing how contexts or spaces are interconnected across time. Interviewees who had been thinking with the Compliance Model saw it as encouraging a middle-term perspective, in terms of the ramifications of Tax Office practices. For example, one interviewee suggested that rather than interpreting the model as suggesting the Tax Office should not prosecute as much, it was rather a way of seeing the effects of prosecutions on future actions, not just on individual taxpayers but also on Australian society as a whole. With this perspective, the aim was not to reach a general consensus on what to do or how to enact the Compliance Model by being given step-by-step instructions. Rather it was about being part of an on-going dialogue about where to go now. As one interviewee commented:

'I don't think you'll ever get consensus. I think genuine commitment is what I think is essential.'

Where did these differences in outlook stem from, between those who thought with and those who thought about the Model? One of the key factors creating these differences were individual experiences of the model, both in terms of attempts to implement it, as well as how their position in the Tax Office affected their personal outlook.

\section{'The view from up here': Considering the lifeworld of Tax Office champions}

Although the management and business lines of the champions in the Tax Office vary, in the way they saw the Compliance Model, they appeared to share some sense of 'vision' in terms of future directions of the Tax Office. In this way, the model appealed as 'intuitive business common sense', as one interviewee put it, as a way to increase compliance and thus increase revenue. Yet, this stance was not only about roles in the Tax Office, but also about how 
work, and experiences in work, affected lifeworlds. 'Lifeworld' here refers to the idea that understanding the Compliance Model was not solely contingent upon narrow work-defined or isolated cognitive processes. Rather, it was related to significant life-experiences, which are given meanings through new forms of learning and experience (Finger 1994). Interviewees' positions in the Tax Office do not just entail performing sets of tasks and adopting a work persona in a detached manner (in comparison to Goffman 1969, Pruzan 2001). Instead, they concerned how their heterogeneous knowledge and experiences (see Latour 1993, Murdoch \& Clark 1994) contributed to seeing the Compliance Model from a certain perspective. For example:

'I think there's certainly a better appreciation of what the model is at senior management level than there is further down. So, I suppose, the level of understanding is still cascading through the organisation. I think there's been more education at the senior level because they are people who are planning our business so they're getting to see the concepts of the model. Like education will teach you about the model, but they actually have to do it and I find models hard until I play with them. I think a lot of the senior management might be the same. When you start looking at business strategy through concepts that are consistent with a model like that then you actually get to see how it can operate and what it's about.'

In contrast to this:

'I mean we have an area called Special Investigations. We work on taskforces with the National Crime Authority and the National Federal Police, basically auditing drug dealers, money launderers, people involved in illegal occupations. So there you see the worst of the world. So that's more painful. With some of our staff who have grown up doing tax audits, that's what they did for years, got rewarded for doing tax audits more quickly and producing more revenue, they've found it quite hard.'

Therefore, it was not only their experiences of the tax system but also experiences of the Compliance Model itself that made a difference to how it was internalised and operationalised. As one interviewee aptly observed:

'People have some resistance to the concept until such time as they personally experience it or see the results.'

The interviews supported this assertion time and time again. Some champions may have intuitively reacted 'we already do that' when first seeing the model, but others suggested that only through 'getting in there' had they come to understand it: 
'I guess it's one of those things that intuitively you have difficulty disputing and we have had that response right through when we have been publicising the model in the Tax Office. People are saying "yes we already do that" and "I suppose that demonstrates our superficial understanding of what it was really about", and "I suppose my initial views were that it wasn't that much different to what we were doing, but the more I explored it and the more I sought to understand it, the more I realised how we weren't really doing those things at all". We were imposing our own will on the market segments that we had created rather than understanding their needs. And instead of looking at what they were doing we were looking at what they should be doing.'

This was often because:

'I could see the relationships and because I've had fairly varied experience in the Office, I could see with the pyramid - you can understand where the taxpayer sits in the world.'

Even those who were sceptical when first seeing the model had their opinions altered when they had worked with the model in their everyday practices:

'My first reaction was 'what's this shit?', not in terms of what the model was trying to say, it was just the language, it was in academia. It wasn't until we started using it at the first conference, when we started playing with some of the ideas in it, that I started to understand it. So I guess for a person like me the worst thing to do was to get me to read something about it. The first thing to do is not even tell me that there's a model. Just start doing some things.'

Thus, how the Compliance Model was viewed was dependent upon how life experiences in the Tax Office had shaped individual perceptions of both tax issues and human nature. For example, champions often stated that tax systems are about 'doing the right thing', not only from the taxpayers' perspective but also from the Tax Office's, in terms of enabling and understanding taxpayers' contextual barriers and personal circumstances:

'My philosophy is that a big percentage of the taxpayers will do the right thing if you just help them do the right thing.'

When asked about the role of the Tax Office in general, two-thirds of interviewees stated that they believed it was about collecting revenue in a fair and reasonable way, and enabling the government to carry out equitable practices of redistribution: 
'Yes, we do have a huge social obligation and we have to make a social contribution, so the way we raise revenue has to be a legitimate form and we fit within social justice, redistribution of wealth.'

Half of these respondents also added that the tax system encompassed issues of community ownership, and confidence that the Tax Office would be fair, just, and listen to an individual's concerns. Indeed, when asked to summarise the strengths of the Compliance Model, just under half said it enabled them to better understand the taxpayers' lives and contexts, enabling them to treat taxpayers more personally, not only with the aim of increasing compliance but also because that is 'how it should be'. This, therefore, was not a neutral or detached position to take on the responsibilities of tax officers. It was instead one bound up with moral and ethical issues beyond the ambit of simply collecting revenue. The ideas represented by the Compliance Model, being abstract, moral and instantly recognisable, were parts of the champion's worldview. As one interviewee stated:

'It just made sense of the world where I live.'

Some interviewees even reported that they, or other staff members, had applied the Compliance Model to their personal relationships with great success!

However, this is not to give the impression that all champions were in agreement about the place that morals and values have in the Tax Office. Some felt that it was essential that staff now bring their values to work with them, and think beyond the office door. Others felt this was a dangerous move, as who judges what is a worthy or right value? Some Tax Office staff felt justified in trying to 'get' rich and famous Australians who, in the public eye too, were not paying their fair share of tax, although they were not doing anything illegal per se. This was not a tax judgment but a moral one, seemingly based on principles of 'fair play' that are believed to be enshrined in the tax system (see also Braithwaite et al 2001 for data on public perceptions of tax in Australia). Ultimately it appeared that champions at least hoped the Compliance Model could lead the way through this ethical minefield. That is, by bringing tax administration and procedural fairness together, through encouraging staff to think about the implications of their practices not just from a revenue perspective but also from a contextual one, the ethics of 'fair play' would become a natural part of Tax Office behaviour. In short, they could persuade members of the public to pay their tax, rather than having to force them to pay. 


\section{Barriers to action: The Tax Office and the structure of practices}

This section considers some possible implications that the champions' ideas may have for future Tax Office practices. There were without doubt multiple barriers to actualising the Compliance Model, which stem partially from translating it from the abstract into action. These barriers were also caused by staff-management relations, administrative structures and the tax system as a legal entity (see Shover et al. 2001). There is also no doubt that champions believed the Compliance Model was good for the Tax Office and that its use should become more widespread within the organisation. The question was how to translate this good idea into practice.

Lower level staff members did not have the luxury of being able to 'play' with the model in their everyday work, as many of the champions have done to come to grips with it. To make up for this lack of direct experience, some champions believed the way forward was to keep pushing the message of the Compliance Model on staff until they finally 'got it':

'I would say people are aware of it and people understand the principles but need ongoing encouragement to continue to do it because it takes time for these things to become automatic so we need to keep working at it so that it becomes automatic.'

Indeed, this assertion seemed to be pretty realistic, as positive change rarely happens overnight. Other interviewees were more strident, suggesting that staff needed to be inculcated and taught to adhere to the Compliance Model. This language of submission and erosion should come as no surprise considering the structuring principles that have framed the Tax Office for so long (see Boucher 1993). The Tax Office has a long history of rigid work practices, of collecting revenue by set means and seeing the taxpayer as the enemy that needs to be outwitted - a mentality that still prevails in some sections according to these interviews (especially audit and prosecution). The Compliance Model ultimately requires that this rigidity be transgressed. This requires a change in both attitudes and actions.

Some champions suggested that a change in attitudes was taking place:

'My observation is that our people feel a greater sense of fulfilment and value through management putting faith and confidence in them being involved in the decisionmaking process.' 
However, these changes were often reported by champions as not working 'on the ground' or 'in the field'. Those working more closely with field staff suggested that changes were not really happening on a day-to-day basis because:

'It doesn't work within the public service delegated authority type regime very well.'

Interviewees were clear that to get over these barriers and have the Compliance Model fully accepted there needed to be a 'culture' change in the Tax Office. This was not an easy task to undertake:

'It takes time. You're stepping over the boundaries a little bit that currently exist and that is a real mind shift, for that to occur.'

'You do see general support. There's probably reluctance though, in stretching the boundaries more so than we've got at the moment. We need to break down some of those paradigms and say "Well, what does it mean for us in the new environment?", and there needs to be space for that thinking and there also needs to be a level of support to take in that work. So I think we're chipping away but we'll probably need to use a bigger pen.'

Yet, is it really feasible or possible to talk about changing an organisational culture by getting staff to rethink their values? For one, the literatures on resistance to behaviour change strongly suggest that giving individuals information on a personal and social problem, and expecting them to then simply change their core beliefs, does not work (see Prochaska \& DiClemente 1986, Prochaska et al. 1992, Rollnick 1996, Wardle 1996). That is, telling people to change their values and beliefs is, to all purposes, a non-starter, especially if done in a manner that even hints at coercion and lack of consultation.

One of the reasons for this, at an organisational level at least, may be that institutions are not merely constituted through disembodied ethics, which can simply be changed as required. Many professions have codes of conduct, such as those factored into the Australian Public Service Act, 1999. These pertain to standards of behaviour that are respectable to others and forward best practice, which can be carried out by individuals who do not necessarily hold certain values but who can professionally undertake actions that embody these values. However, having these service values differs considerably from a Chief Executive suddenly proclaiming 'this is all how we are now going to think and react from here on', in the expectation that all desired change will then follow (in comparison to Pruzan 2001). In 
everyday life, and also epistemologically, there is no separation between values and actions. That is, the 'culture' of the Tax Office, which interviewees refer to on many occasions, is embodied and perpetuated through individual and collective routine practices, be it the way officers talk to taxpayers, or the way information is processed ${ }^{7}$.

The champions who thought with the Compliance Model were able to see this potential catch-22. They did not simply call for structures or values to be changed but recognised that they are all inextricably linked in indecipherable complex ways:

'I mean the trouble is with an organisation - at a level where you start looking, at the whole people system - everything's damn well integrated. It's the identity, it's the culture, it's the kind of way that leaders lead, it's all that stuff. I find that all a bit daunting.'

Indeed, daunting it is. A parallel example can be made from the environmental change literature. Some environmental researchers suggest that changing behaviour without changing values is adequate (this is called Applied Behaviour Analysis: see Geller 1989). A second view is that technology and the processes of widespread ecological modernisation have the answers (see Cohen 1998). A third approach argues that values of 'deep ecology' have to be nurtured before wide-scale environmental improvements can be seen (see Pepper 1996). The Tax Office faces a similar issue but on a smaller scale. That is, how to create the widespread acceptance of a new way of thinking and acting that is fundamentally moral? If Giddens is used constructively, it can be suggested that changing practices is the best way forward. As one interviewee suggested:

'I think it's just about keeping it fairly simple to start with. Just starting with some fairly simple sorts of changes. We ran some fairly small pilots that were able to actually demonstrate some changes that it made. I guess it's about actually making it practical for staff. It just clicks with people. That one message. If you started with that you've gone somewhere, you've gotten somewhere with it - and then if you come back again and you talk about "let's do something else", you just get that gradual change I suppose.'

\footnotetext{
${ }^{4}$ For example, several interviewees made reference to the way current Information Technology systems did not allow them to access information required for a 'complete picture' of individual taxpayer's circumstances and history. Yet understanding history and circumstances is at the heart of implementation of the Compliance Model.
} 
Thus, altering practices so that they embody the Compliance Model ideas seems to be the most practicable way forward. This assertion can be supported by research the author carried out into individuals taking part in a sustainable consumption behaviour change program in the UK, called Action at Home (see Hobson 2001a and 2001b). Over a six month period, it was found that many participants of Action at Home only changed a few small, seemingly mundane practices, such as turning off the taps when brushing their teeth or switching lights off when leaving the room. However, what was significant were the changes in personal outlooks that resulted from participants thinking about the social and environmental implications of their previous habits, and their reconsiderations of the types of attitudes these previous practices embodied. Issues such as water and energy use were brought from the practical to discursive consciousness, making individuals ask themselves why they carried out certain actions the way they did, and what the ramifications of their actions might be. The resultant magnitude of behaviour change may not appear significant. However, it seemed to leave behind a 'lens of difference'. This means that participants were left with a residual awareness of the issues that Action at Home discussed. They had not become converted to being 'green' but had internalised a consideration for the environment that touched and subtly affected the way they viewed the world and their own behaviour.

The same could be argued for the Tax Office. By altering small practices, Tax Office staff were experiencing the Compliance Model in action, and are carrying out the principles of the Compliance Model without having it overtly enforced. This is a small but important step forward in getting Tax Office staff to rethink their practices. One interviewee made this point well by drawing out the difference between rules, and moral philosophy or values. That is, rules are clear-cut but values are debatable. Tax Office staff prefer to have judgments handed down, even if they are not 'fair' in their outcomes. Therefore who decides what the 'right thing' is?

'I just don't see how you can not make a philosophy work. You can make a set of rules not work. Our general approach is that there is a set of values behind your work. If those values don't fit the work you are doing then there's something wrong with them but I haven't found that to be the case with the Compliance Model. Whereas if we applied it as a set of rules - 'this is the way you do things now' - then I think we would often find times where it doesn't fit.' 
Thus, if the Tax Office is to make the Compliance Model work into the future, there needs to be a consideration of how new practices can be encouraged that embody and carry forward the messages and principles of the Model. It is not about trying to create new values, but rather put into action the ideas of the Compliance Model through small changes to practices.

Examining briefly the processes through which the Compliance Model appears to have made an impact in the Tax Office supports this assertion. For one, there are the 'above the line' examples, such as embedding it into Tax Office recruitment strategies. Making the Compliance Model part of staff's everyday thinking is partially a result of these official stances. For example, the need for strong leadership in the Tax Office was stressed time and time again in reference to making the Compliance Model work (also see Bouwen \& Fry 1988, Hooper \& Potter 1999, Shover et al. 2001). Yet, there appear to be other processes involved - ones 'below the line' of official managerial practice - that are equally important and hinge upon the Compliance Model being translated into everyday behaviours for staff, either by champions involved in training or through the informal 'mentoring' of staff. As champions were able to think with the model, they clearly saw that the translation process of the model from the abstract into the everyday requires tapping into the knowledge and language of Tax Office staff, not simply expecting them to jump 'cultures' as the result of one presentation or meeting.

For example, one interviewee talked about how the language of the Compliance Model had been changed to enable it to resonate with Tax Office staff:

'Originally we used to have some delineations within the compliance pyramid that showed education advice here and then audit here and people love to box things so they kind of saw it was a static kind of model. So, when I introduced it to people the first thing you had to do is - when it had that language on it - was take it all off. Let people use their own words and let them write their own words on the model so that then they could be engaged.'

Another champion told of how she used stories to translate the model into reality. Through detailing to other staff her own personal experiences of the Tax Office, in trying to correctly lodge her personal tax returns and feeling that she was treated as guilty until proven innocent by the Tax Office, she was able to bring the model to life for staff. In training sessions: 
'I read them the letter 5 Gnd they said "Oh!". So practically I could say "see, this is what's happening". So I was able to use that story. That story worked wonders.'

The same interviewee later explained why telling stories of actual experiences, using Tax Office language and processes, works:

'But when you actually say in their language "well you know when you do blah blah blah procedure? Dah, dah, dah happens." As soon as you say that, you've got them hooked because they think "She's one of us!".'

The importance of making these initial connections with the Compliance Model cannot be underestimated as many champions reported how staff switched off from the model in presentations, saying it had nothing to do with them and their line of work. Therefore:

'It's really about taking it from a model and making it real for people, which was the important step.'

Being able to make this initial connection then enabled staff to understand and work with the Compliance Model, to get into the model rather than feeling they had this rigid entity into which they must squeeze their work. As one interviewee put it:

'Instead of chipping away, these things could just be like a snowball running down the hill, it would really feed on itself.'

There were signs that a snow-ball effect was happening, as many champions were positive that the Compliance Model was making an impact on the Tax Office, although there are still many barriers to overcome (see Hobson and Job, forthcoming). The key point to make is that changes were happening through staff using the model, talking to others about it, and seeing its positive benefits for themselves:

'When I first went around the country to talk to my teams, I got the same response "it's just a waste of time. All taxpayers are cheats". But fortunately when team members actually have gone out and applied the concept or used this strategy, they personally see the result that comes of it. Therefore, there's a change in mind-set, to be more accepting of the concept.'

\footnotetext{
${ }^{5}$ This letter was received by the interviewee from the Tax Office after she had failed to lodge correctly. The interviewee felt the tone of the letter made the assumption that she was trying to cheat on her tax payments.
} 
These can be seen as processes of social learning and social diffusion. Rogers (1995) argues that an individual's adoption of innovations stems not just from reading about an innovation but from listening to and witnessing how other individuals in their social network have evaluated the innovation (see also Flinn 1997 for further discussion of social learning). Talk between Tax Office staff and others, be it informal or formal, is important as change is achieved through communication and negotiation, as well as through simply watching others. This is social learning. The adoption of new ideas can rarely be imposed from the outside (Harrisson et al. 2001) but instead takes place along 'learning-action' networks (Clarke \& Roome 1999), which cut across formal organisational hierarchies and boundaries. This is social diffusion. Thus, bringing the Compliance Model to life is not about individuals singularly adopting the Compliance Model internally and then putting it into action in tangent with others. It is instead a process of 'joint action' (Shotter 1993a, 1993b), facilitated through different processes of learning.

De Young's (1993) typology of behaviour change processes makes this point. He suggests that both tangible and intangible processes of behaviour change exist. Examples of tangible forms are feedback, material incentives and legal mandates, whilst intangible forms can be direct experience, personal insight, self-monitored feedback, and a sense of confidence and commitment. The point to be taken from this is that adoption of the Compliance Model in the Tax Office should not be about employing just one of these forms of change. Instead, it requires a mixture of leadership, support, information, policy reworking, personal experience, commitment to change, and broad thinking. The Compliance Model champions appear to embody and encompass this broad array of behaviour change processes, enabling them to think with the model and offering interesting insights into how change might be forwarded in organisations such as the Tax Office. 


\section{CONCLUSIONS}

This paper has sought to address why certain individuals in the Tax Office can be considered Compliance Model champions. It has attempted to offer an alternate story from positivist approaches, by examining how these individuals talked about the Compliance Model and its place in their lifeworld. Through this 'below the line' approach the themes of experience, social learning and interaction have emerged as positive aspects of change. Yet the departing message of this research should not be read as advocating all Tax Office staff adopt 'touchyfeely' approaches, as several interviewees put it. The Tax Office has to administer tax laws across a large and diverse country, a task that requires procedures and systems able to cope with vast quantities of information and assessments. The messages are rather that the lifeworld of many Tax Office staff is such that the Compliance Model would not have immediate resonance in relation to their everyday experiences. Thus, the process of translation is important. Often this translation is believed to involve either changing the wholesale 'culture' of the Tax Office or turning the Compliance Model into a step-by-step rulebook. This research advocates a more middle-ground approach from the lessons the champions have to offer, by examining how small practices embody the central tenets of the Compliance Model. As a result, it encourages the taking of a gradual, iterative approach to change.

This research can also reflect on implications for how taxpayers are treated. In the spirit of reflexivity, it is hoped that organisations like the Tax Office might conclude that their own staff's rejection or disengagement from the abstract form of the Compliance Model might give some insight into how the taxpayer struggles with tax returns. Do they speak to the 'world where they live', as many Tax Office staff initially felt the Compliance Model did not? Why should the taxpayer comply with a set of regulations or practices that do not take into account the constraints and lack of adequate infrastructure in their everyday lives, when some Tax Office staff feel exactly the same way about the Compliance Model? Funnily enough, this argument brings this research full circle, back to the model itself. The fact that this research supports a 'below the line' approach to encouraging changes in practice can be seen as offering support to the central tenets of the Compliance Model. That is, by understanding the consequences of one's actions and the messages embodied in practices, we can begin to understand and positively affect other's practices and bring them into a more supportive and compliant environment, whether we are talking about Tax Office staff or the taxpaying community at large. 


\section{REFERENCES}

Ajzen, I. \& Fishbein, M. (1980). Understanding Attitudes and Predicting Social Behaviour, Prentice-Hall.

Australian Bureau of Statistics (2001). Labour: Characteristics of Employment, ABS.

Billig, M. (1987). Arguing and Thinking: a rhetorical approach to social psychology, Cambridge University Press.

Billig, M. (1993). Studying the thinking society: social representations, rhetoric and attitudes. In Breakwell, G. M. \& Canter, D. V. (eds), Empirical Approaches to Social Representations, Clarendon Press.

Boden, D. (1994). The Business of Talk, Polity Press.

Boucher, T. (1993). Risk Management on a Market Segmented Basis, in Grabosky, P. \& Braithwaite, J. (eds) Business Regulation and Australia's Future. Canberra: Australian Institute of Criminology.

Bouwen, R. \& Fry, R. (1988). An agenda for managing organizational innovation and development in the 1990s. In Lambrecht, M. (ed), Corporate Revival: managing into the Nineties, Leuven University Press.

Braithwaite, V., Reinhart, M., Mearns, M. \& Graham, R. (2001). Preliminary findings from the Community Hopes, Fears and Actions Survey. Centre for Tax System Integrity Working Paper No. 3. Canberra: Australian National University.

Burgess, J., Limb, M. \& Harrison, C. (1988a). Exploring environmental values through the medium of small groups: 1. Theory and Practice. Environment and Planning A, 20: 309-326. Burgess, J., Limb, M. \& Harrison, C. (1988b). Exploring environmental values through the medium of small groups: 2. Illustrations of a group at work. Environment and Planning A, 20: 457-476. 
Burningham, K. \& Cooper, G. (1999). Being Constructive: Social Constructionism and the Environment. Sociology, 33(2): 297-316.

Clarke, S. \& Roome, N. (1999). Sustainable Business: Learning-Action Networks as Organizational Assets. Business Strategy and the Environment, 8: 296-310.

Cohen, M. J. (1998). Science and Environment: assessing cultural capacity for ecological modernization. Public Understanding of Science, 7: 149-167.

Damapour, F. \& Gopalakrishnan, S. (2001). The Dynamics of the Adoption of Product and Process Innovations in Organizations, Journal of Management Studies, 38(1): 45-65

De Young, R. (1993). Changing Behavior and Making it Stick: the Conceptualization and Management of Conservation Behavior. Environment and Behavior, 25(4): 485-505.

Denzen, N. K. \& Lincoln, Y. S. (1998). Introduction: Entering the Field of Qualitative Research. In N. K. Denzin \& Lincoln, Y. S. (ed), The Landscape of Qualitative Research; theories and issues, Sage Publications.

Edwards, D., Ashmore, M. \& Potter, J. (1995). Death and Furniture: the rhetoric, politics and theology of bottom line arguments against relativism. History of the Human Sciences, 8(2): 25-49.

Ehrlich, P. R., Wolff, G., Daily, G. C., Hughes, J. B., Daily, S., Dalton, M. \& Goulder, L. (1999). Knowledge and the Environment. Ecological Economics, 30: 267-284.

Farr, R. M. (1993). Common sense, science and social representations. Public Understanding of Science 2.

Finger, M. (1994). From Knowledge to Action? Exploring the Relationship Between Environmental Experiences, Learning and Behavior. Journal of Social Issues, 50(3): 141160. 
Fishbein, M. (1993). Introduction. In Gallois, C., McCamish, M. \& Terry, D. J. (eds), The Theory of Reasoned Action: its application to AIDS-preventive behaviour, Pergamon Press, Oxford.

Flinn, M. V. (1997). Culture and the Evolution of Social Learning. Evolution and Human Behavior, 18(1): 23-67.

Frey, J. H. \& Fontana, A. (1993). "The Group Interview in Social Research". In Morgan, D. L. (ed), Successful Focus Groups: advancing the state of the art, Sage Publications: 20-34.

Geller, E. S. (1989). Applied Behavior Analysis and Social Marketing: An Integration for Environmental Preservation. Journal of Social Issues, 45(1): 17-36.

Giddens, A. (1984). The Constitution of Society, Polity Press.

Goffman, E. (1969). The presentation of self in everyday life, London Penguin.

Gray, D. B. (1985). Ecological Beliefs and Behaviour, Greenwood Press.

Harrison, C. M., Burgess, J. \& Filius, P. (1996). Rationalizing Environmental Responsibilities: A comparison of lay publics in the UK and Netherlands. Global Environmental Change, 6(3): 215-234.

Harrisson, D., Laplante, N. \& St-Cyr, L. (2001). Cooperation and resistance in work innovation networks, Human Relations 54(2): 215-255

Harvey, D. (2000). Spaces of Hope. Berkeley: University of California Press.

Hinchliffe, S. (2000). Performance and experimental knowledge: outdoor management training and the end of epistemology. Environment and Planning D, 18: 575-595.

Hobson, K. (2001a). Talking Habits into Action: An investigation into Global Action Plan's 'Action at Home' programme, Unpublished doctoral dissertation. London: University College London. 
Hobson, K. (2001b). Sustainable Lifestyles: Rethinking barriers and Behaviour change. In Cohen, M. J. \& Murphy, J. (eds), Exploring Sustainable Consumption: Environmental Policy and the Social Sciences, Elsiver.

Hollingsworth, J. R. (2000). Doing Institutional Analysis: implications for the study of innovations, Review of International Political Economy, 7(4): 595-644.

Hooper, A. \& Potter, J. (1999). Take it from the top, People Management 5(16): 46-49.

Huguet, P., Latane, B. \& Bourgeois, M. (1998). “The emergence of a social representation of human rights via interpersonal communication: empirical evidence for the convergence of two theories.” European Journal of Social Psychology 28: 831-846.

Jaspars, J. \& Fraser, C. (1984). Attitudes and social representations. In Farr, R. M. \& Moscovici, S. (ed), Social Representations, Cambridge University Press.

Kanter, R. M. (1983). The Change Masters, Simon \& Schuster, New York.

Kanter, R. M. (1989). When Giants Learn to Dance, Simon \& Schuster, New York.

Karp, D. G. (1996). Values and Their Effect on Pro-Environmental Behavior. Environment and Behavior, 28(1): 11-133.

Kilminster, R. (1991). Structuration theory as a world-view. In Bryant, C. G. A. \& Jary, D. (eds), Giddens' Theory of Structuration: A critical appreciation, Routledge: 74-115.

King, N. (1990). Innovation at work: the research literature. In West, M. A. \& Farr, J. L. (eds) Innovation and Creativity at Work. John Wiley \& Sons.

Klein, N. (2000). No Logo. Flamingo.

Kruse, L. \& Schwarz, S. (1992). Who Pays the Bill? The Language of Social Representation. In von Cranach, M., Doise, W. \& Mugny, G. (eds), Social Representations and the Social Bases of Knowledge, Hogrefe \& Huber. Swiss Monographs in Psychology: 23-29. 
Kvale, S. (1996). InterViews: An introduction to Qualitative Research Interviewing. Sage Publications.

Lalli, P. (1999). New Challenges for social communication about health. Alcologia: European Journal of Alcohol Studies, 2: 1-11.

Latour, B. (1993). We Have Never Been Modern, Harvester Wheatsheaf.

Macnaghten, P. \& Urry, J. (1998). Contested Natures, Sage publications.

McKinlay, A., Potter, J. \& Wetherall, M. (1993). Discourse Analysis and Social Representations. In Breakwell, G. M. \& Canter, D. V. (eds), Empirical Approaches to Social Representations, Clarendon Press.

Mills, S. (1998). Discourse, Routledge.

Moscovici, S. (2001). Social Representations, New York University Press.

Murdoch, J. \& Clark, J. (1994). Sustainable Knowledge, Geoforum 25 (2), 115- 132.

Pepper, D. (1996). Modern Environmentalism, Routledge.

Prochaska, J. \& DiClemente, C. C. (1986). Toward a comprehensive model of change. In Miller, W. \& Heather, N. (eds), Addictive Behaviours: processes of change, Plenum Press.

Prochaska, J. O., DiClemente, C. C. \& Norcross J. C. (1992). In Search of How People Change: application to addictive behaviors. American Psychologist, 47(9): 1102-1114.

Pruzan, P. (2001). The question of organizational consciousness: Can organizations have values, virtues and visions? Journal of Business Ethics, 29(3): 271-284.

Public Service and Merit Protection Commission (2000). Australian Public Service Values. http://www.psmpc.gov.au/publications/values.htm. 
Reser, J. P. (1995). Whither Environmental Psychology? The Transpersonal Ecopsychology Crossroads. Journal of Environmental Psychology, 15: 235-257.

Rogers, E. M. (1995). Diffusion of Innovations, Free Press.

Rollnick, S. (1996). Behaviour change in practice: targetting individuals. International Journal of Obesity Related Metabolic Disorders, 20(supplement 1): 22-6.

Rosenfeld, R., \& Servo, J. C. (1990). Facilitating innovations in large organization. In West, M. A. \& Farr, J. L. (eds) Innovation and Creativity at Work, John Wiley \& Sons.

Shotter, J. (1993a). Cultural Politcs of Everyday Life: Social Constructionism, Rhetoric and Knowing of the Third Kind, Open University Press.

Shotter, J. (1993b). Conversational Realities, Sage Publications.

Shover, N., Job, J., \& Carroll, A. (2001). Organisational capacity for responsive regulation. Centre for Tax System Integrity Working Paper No. 15. Canberra: The Australian National University.

Sibeon, R. (1999). Anti-Reductionist Sociology. Sociology, 33(2): 317-334.Publications.

Strauss, A. L. (1987). Qualitative Analysis for Social Scientists, Cambridge University Press.

Strauss, C. \& Quinn, N. (1997). A Cognitive Theory of Cultural Meaning, Cambridge University Press.

Stubbs, M. (2000). Action, Knowledge and Business-Environment Research: A Case for Grounded Constitutive Process Theories and a Sense of Audience. Business Strategy and the Environment, 9: 24-35.

Terry, D., Gallois, C., et al. (1993). Reasoned action and Health Care Behaviour. In Gallois, C., McCamish, M. \& Terry, D. J. (eds), The Theory of Reasoned Action: its application to AIDS-preventive behaviour. 
Visser, B. (2000). Organizational communication structure and performance, Journal of Economic Behaviour and Organization, 42: 231-252.

Walker, R. (1985). An Introduction to Applied Qualitative Research. In Walker, R. (ed), Applied Qualitative Research, Gower: 3-26.

Wardle, J. (1996). Obesity and Behaviour Change: matching problems to practice. Intenational Journal of Obesity Related Metabolic Disorders, 20 (supplement 1): 1-8.

Welford, R. J. (1998). Corporate Environmental Management, Technology and Sustainable Development: Postmodern Perspectives and the Need for a Critical Research Agenda. Business Strategy and the Environment, 7: 1-12.

West, M.A. \& Farr, J. L. (1990). Innovation at Work in West. In West, M. A.\& Farr, J. L., (eds) Innovation and Creativity at Work, John Wiley \& Sons. 


\section{THE CENTRE FOR TAX SYSTEM INTEGRITY WORKING PAPERS}

No. 1. Braithwaite, V. \& Reinhart, M. The Taxpayers' Charter: Does the Australian Taxation Office comply and who benefits? December 2000.

No. 2. Braithwaite, V. The Community Hopes, Fears and Actions Survey: Goals and Measures. March 2001.

No. 3. Braithwaite, V., Reinhart, M., Mearns, M. \& Graham, R. Preliminary findings from the Community Hopes, Fears and Actions Survey. April 2001.

No. 4. Mearns, M., \& Braithwaite, V. The Community Hopes, Fears and Actions Survey: Survey method, sample representativeness and data quality. April 2001.

No. 5. Sakurai, Y., \& Braithwaite, V. Taxpayers' perceptions of the ideal tax adviser: Playing safe or saving dollars? May 2001.

No. 6. Wenzel, M. The impact of outcome orientation and justice concerns on tax compliance: The role of taxpayers' identity. June 2001.

No.7. Wenzel, M. Misperceptions of social norms about tax compliance (1): A prestudy. June 2001.

No. 8. Wenzel, M. Misperceptions of social norms about tax compliance (2): A fieldexperiment. June 2001.

No.9. Taylor, N. Taxpayers who complain about paying tax: What differentiates those who complain from those who don't? June 2001.

No. 10. Wenzel, M. Principles of procedural fairness in reminder letters and awareness of entitlements: A prestudy. June 2001.

No. 11. Taylor, N. \& Wenzel, M. The effects of different letter styles on reported rental income and rental deductions: An experimental approach. July 2001.

No. 12. Williams, R. Prosecuting non-lodgers: To persuade or punish? July 2001.

No. 13. Braithwaite, V. Tensions between the citizen taxpaying role and compliance practices. Forthcoming.

No. 14. Taylor, N. Understanding taxpayer attitudes through understanding taxpayer identities. July 2001.

No. 15. Shover, N., Job, J. \& Carroll, A. Organisational capacity for responsive regulation. August 2001. 
No. 16. Tyler, T.R. Trust and law-abidingness: A proactive model of social regulation. August 2001.

No. 17. Genser, B. Corporate income taxation in the European Union: Current state and perspectives. August 2001.

No. 18. McBarnet, D. When compliance is not the solution but the problem: From changes in law to changes in attitude. August 2001.

No. 19. Schneider, F., Braithwaite, V. \& Reinhart, M. Individual behaviour in Australia's shadow economy: Facts, empirical findings and some mysteries. September 2001.

No. 20. Taylor, N. \& Wenzel, M. Comparing rental income and rental deductions for electronic versus paper lodgers: A follow-up investigation. November 2001.

No.21. Braithwaite, J. Through the eyes of the advisers: A fresh look at tax compliance of high wealth individuals. September 2001.

No. 22. Braithwaite, J., Pittelkow, Y. \& Williams, R. Tax Compliance by the very wealthy: Red flags of risk. September 2001.

No. 23. Braithwaite, J. \& Williams, R. Meta risk management and tax system integrity. October 2001.

No. 24. Braithwaite, J. \& Wirth, A. Towards a framework for large business tax compliance. November 2001.

No. 25. Murphy, K. \& Sakurai, Y. Aggressive Tax Planning: Differentiating those playing the game from those who don't. October 2001.

No. 26. Morgan, S. \& Murphy, K. The 'Other Nation': Understanding rural taxpayers' attitudes towards the Australian tax system. Forthcoming.

No. 27. Ahmed, E. \& Sakurai, Y. Small business individuals: What do we know and what do we need to know? Forthcoming.

No. 28. Hobson, K. Championing the compliance model: From common sense to common action? December 2001. 